NASA/TM-2005-213371

Electric Propulsion Concepts Enabled by High Power Systems for Space Exploration

James Gilland

Ohio Aerospace Institute, Brook Park, Ohio

Douglas Fiehler

QSS Group, Inc., Cleveland, Ohio

Valerie Lyons

Glenn Research Center, Cleveland, Ohio 
Since its founding, NASA has been dedicated to the advancement of aeronautics and space science. The NASA Scientific and Technical Information (STI) Program Office plays a key part in helping NASA maintain this important role.

The NASA STI Program Office is operated by Langley Research Center, the Lead Center for NASA's scientific and technical information. The NASA STI Program Office provides access to the NASA STI Database, the largest collection of aeronautical and space science STI in the world. The Program Office is also NASA's institutional mechanism for disseminating the results of its research and development activities. These results are published by NASA in the NASA STI Report Series, which includes the following report types:

- TECHNICAL PUBLICATION. Reports of completed research or a major significant phase of research that present the results of NASA programs and include extensive data or theoretical analysis. Includes compilations of significant scientific and technical data and information deemed to be of continuing reference value. NASA's counterpart of peerreviewed formal professional papers but has less stringent limitations on manuscript length and extent of graphic presentations.

- TECHNICAL MEMORANDUM. Scientific and technical findings that are preliminary or of specialized interest, e.g., quick release reports, working papers, and bibliographies that contain minimal annotation. Does not contain extensive analysis.

- CONTRACTOR REPORT. Scientific and technical findings by NASA-sponsored contractors and grantees.
- CONFERENCE PUBLICATION. Collected papers from scientific and technical conferences, symposia, seminars, or other meetings sponsored or cosponsored by NASA.

- SPECIAL PUBLICATION. Scientific, technical, or historical information from NASA programs, projects, and missions, often concerned with subjects having substantial public interest.

- TECHNICAL TRANSLATION. Englishlanguage translations of foreign scientific and technical material pertinent to NASA's mission.

Specialized services that complement the STI Program Office's diverse offerings include creating custom thesauri, building customized databases, organizing and publishing research results ... even providing videos.

For more information about the NASA STI Program Office, see the following:

- Access the NASA STI Program Home Page at http://www.sti.nasa.gov

- E-mail your question via the Internet to help@sti.nasa.gov

- Fax your question to the NASA Access Help Desk at 301-621-0134

- Telephone the NASA Access Help Desk at 301-621-0390

- Write to:

NASA Access Help Desk

NASA Center for AeroSpace Information 7121 Standard Drive

Hanover, MD 21076 
NASA/TM-2005-213371

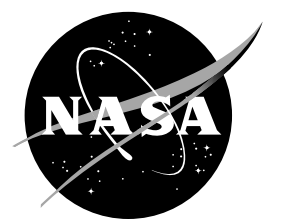

\section{Electric Propulsion Concepts Enabled by High Power Systems for Space Exploration}

James Gilland

Ohio Aerospace Institute, Brook Park, Ohio

Douglas Fiehler

QSS Group, Inc., Cleveland, Ohio

Valerie Lyons

Glenn Research Center, Cleveland, Ohio

Prepared for the

Second International Energy Conversion Engineering Conference sponsored by the American Institute of Aeronautics and Astronautics Providence, Rhode Island, August 16-19, 2004

National Aeronautics and

Space Administration

Glenn Research Center 


\section{Acknowledgments}

The authors would like to thank Leon Gefert and Tim Sarver-Verhey for the use of their Mars EP data in the generation of Figure 9 and Steve Oleson for Figure 10.

Available from

NASA Center for Aerospace Information 7121 Standard Drive

Hanover, MD 21076
National Technical Information Service 5285 Port Royal Road Springfield, VA 22100

Available electronically at http:/ /gltrs.grc.nasa.gov 


\title{
Electric Propulsion Concepts Enabled by High Power Systems for Space Exploration
}

\author{
James Gilland \\ Ohio Aerospace Institute \\ Brook Park, Ohio 44142 \\ Douglas Fiehler \\ QSS Group, Inc., \\ Cleveland, Ohio 44135 \\ Valerie J. Lyons \\ National Aeronautics and Space Administration \\ Glenn Research Center \\ Cleveland, Ohio 44135
}

This paper describes the latest development in electric propulsion systems being planned for the new Space Exploration initiative. Missions to the Moon and Mars will require these new thrusters to deliver the large quantities of supplies that would be needed to support permanent bases on other worlds. The new thrusters are also being used for unmanned exploration missions that will go to the far reaches of the solar system. This paper is intended to give the reader some insight into several electric propulsion concepts - their operating principles and capabilities, as well as an overview of some mission applications that would benefit from these propulsion systems, and their accompanying advanced power systems.

\section{Nomenclature}

$\begin{array}{ll}\mathrm{A}_{\mathrm{g}} & \text { ion thruster grid area } \\ a & \text { vehicle acceleration } \\ \mathbf{B} & \text { Magnetic Field strength } \\ \mathrm{b}, \mathrm{d} & \text { empirical terms related to the losses due to plasma production and acceleration } \\ \mathrm{DC} & \text { Direct Current } \\ \mathrm{EP} & \text { Electric Propulsion } \\ \mathrm{g}_{\mathrm{o}} & \text { gravitational constant } \\ \mathrm{h} & \text { hours } \\ \mathrm{I}_{\mathrm{sp}} & \text { specific impulse } \\ \mathrm{J} & \text { parameter characteristic of the mission difficulty } \\ \mathrm{J}_{\mathrm{b}} & \text { ion current flux through the grids } \\ \boldsymbol{J} & \text { current through thruster } \\ \boldsymbol{J}_{\mathrm{XB}} & \text { Lorentz force arising from orthogonal currents and magnetic fields } \\ \boldsymbol{J}_{\boldsymbol{\theta}} & \text { azimuthal thruster current } \\ \Delta \mathrm{V} & \text { change in velocity } \\ \dot{m} & \text { mass flow rate of propellant } \\ \mathrm{M}_{\mathrm{i}} & \text { vehicle initial mass } \\ \mathrm{M}_{\mathrm{f}} & \text { propellant mass } \\ \mathrm{M}_{\mathrm{t}} & \text { propulsion system mass } \\ \mathrm{M}_{\mathrm{l}} & \text { payload mass } \\ \mathrm{MPD} & \text { magnetplasmadynamic } \\ \mathrm{NEP} & \text { Nuclear Electric Propulsion } \\ \mathrm{P}_{\mathrm{e}} & \text { power input to the thruster } \\ \mathrm{T} & \text { thruster operating time } \\ \mathrm{T}_{\mathrm{MPD}} & \text { value of thrust from an MPD thruster } \\ & \end{array}$


$\mathrm{V}_{\mathrm{b}} \quad$ voltage which accelerates the ions

$\alpha \quad$ specific mass

$\mu \quad$ actual vehicle payload fraction, $M_{1} / M_{i}$

$\eta \quad$ efficiency

\section{Introduction}

As space power research provides the technology to build future space vehicles with advanced nuclear systems, this enables electric propulsion devices that require kilowatts to megawatts of power. Larger diameter, higher $\mathrm{I}_{\mathrm{sp}}$ ion thrusters and Hall thrusters are being built and tested in vacuum chambers jointly with advanced high power system concepts such as Brayton systems. High power electric propulsion devices are being built and demonstrated in the laboratory, such as Magnetoplasmadynamic (MPD) thrusters and Pulsed Inductive Thrusters (PIT).

This paper describes the latest developments in electric propulsion systems being planned for the new Space Exploration initiative. Missions to the Moon and Mars will require these new thrusters to deliver the large quantities of supplies that would be needed to support permanent bases on other worlds. The new thrusters are also being used for unmanned exploration missions that will go to the far reaches of the solar system. This paper is intended to give the reader some insight into several electric propulsion concepts - their operating principles and capabilities, as well as an overview of some mission applications that would benefit from these propulsion systems, and their accompanying advanced power systems.

\section{Generic Thruster Figures of Merit}

A vehicle propelled by electric propulsion will, of course follow the standard rocket equation:

$$
\frac{\mathrm{M}_{\mathrm{f}}}{\mathrm{M}_{\mathrm{i}}}=\mathrm{e}^{-\Delta \mathrm{V} / \mathrm{gI}_{\mathrm{sp}}}
$$

This holds true for any propulsion system, and demonstrates the benefit of high $I_{\mathrm{sp}}$. $\mathrm{I}_{\mathrm{sp}}$ is the ratio of thrust to weight flow rate of propellant at sea level, $\mathrm{I}_{\mathrm{sp}}=\mathrm{T} /\left(\mathrm{g}_{0} \dot{m}\right)$, and is proportional to the rocket exhaust velocity. Some refinements due to the nature of a power-limited system such as EP require some different forms of the above equation, which will be offered here without derivation. The first form of the low-thrust rocket equation is

$$
\frac{1}{\mathrm{M}_{\mathrm{f}}}-\frac{1}{\mathrm{M}_{\mathrm{i}}}=\frac{1}{2 \eta \mathrm{P}_{\mathrm{e}}} \int_{0}^{\mathrm{T}} \mathrm{a}(\mathrm{t})^{2} \mathrm{dt}=\frac{\mathrm{J}}{2 \eta \mathrm{P}_{\mathrm{e}}}
$$

where " $\mathrm{a}$ " is the vehicle acceleration, and the "J" parameter is a characteristic of the mission difficulty, much like $\Delta \mathrm{V}$ is for a high thrust mission. $\mathrm{J}$ is a mission invariant for low thrust systems, whereas $\Delta \mathrm{V}$ often is not ${ }^{1}$. Equation 2 further differs from a high thrust relationship in that the $\mathrm{M}_{\mathrm{f}}$ term includes the propulsion system $\mathrm{mass}_{(\mathrm{t}}\left(\mathrm{M}_{\mathrm{t}}\right)$, which can be comparable to the payload mass $\left(\mathrm{M}_{1}\right)$. The propulsion system, including power and thrusters, is often parameterized by the specific mass, $\alpha$, expressed in $\mathrm{kg} / \mathrm{kWe}: M_{t}=\alpha \mathrm{P}_{e}$.

A third version of the low thrust rocket equation shows the relative role of all the power and propulsion system performance parameters in mission analysis ${ }^{2}$ :

$$
\mathrm{e}^{-\Delta \mathrm{V} / \mathrm{g}_{0} \mathrm{I}_{\mathrm{sp}}}=\frac{\mu+\frac{\alpha \mathrm{g}_{0}{ }^{2} \mathrm{I}_{\mathrm{sp}}{ }^{2}}{2 \eta \mathrm{T}}}{1+\frac{\alpha \mathrm{g}_{0}{ }^{2} \mathrm{I}_{\mathrm{sp}}{ }^{2}}{2 \eta \mathrm{T}}}
$$


Where $\mu$ is the actual vehicle payload fraction, $\mathrm{M}_{1} / \mathrm{M}_{\mathrm{i}}$ and $\mathrm{T}$ is the thruster operating time. Equation 3 can be used to assess the effects of various thruster performance parameters to determine optimal operating conditions. The result of such analysis is to show that there is an optimal specific impulse for a given mission that results in the maximum payload fraction $(\mu)^{3}$. The optimum $I_{\mathrm{sp}}$ is usually not the highest $\mathrm{I}_{\mathrm{sp}}$ attainable. A detailed analysis would also include the variation of $\eta$ with $I_{\mathrm{sp}}$, as is experimentally observed in electric propulsion thrusters. System performance can be characterized in terms of the repeating parameter in Equation 3:

$$
\frac{\alpha g_{0}{ }^{2} I_{s p}{ }^{2}}{2 \eta T}
$$

While Eq. 3 is a complex, transcendental equation, the general trend is that Eq. 4 should be small compared to unity to increase $\mu$. If the Isp is significantly higher than the mission difficulty $(\Delta \mathrm{V})$, the exponential term becomes insensitive to Isp, and the variation of Eq. 4 becomes the dominant effect. This translates to low $\alpha$, high $\eta$, long T, and the minimum $I_{\text {sp }}(>>\Delta V)$ to accomplish the mission. Note that the $\alpha$ term is generally dominated by the power system mass, so that the thruster-specific term is then

$$
\frac{I_{s p}^{2}}{2 \eta T}
$$

For nominal NEP system parameters of $10 \mathrm{~kg} / \mathrm{kWe}, 5000 \mathrm{~s}$ Isp, $0.6 \eta$, and an operating time of 10,000 hours, Eq. 4 has a value of 0.12 . For a $\Delta V$ of $20 \mathrm{~km} / \mathrm{s}$, the corresponding $\mu$ is $\sim 0.63$.

Unspecified in this discussion, and beyond the scope of this discussion, are the power and lifetime requirements of the system and how they affect the mission design. In brief, Eq. 5 is related to a power per unit propellant mass, and the higher its value, the greater the power. Thus, the above relation can also be used to calculate power requirements for various missions. ${ }^{3}$ Power requirements have been reviewed above. Thruster lifetime plays a role in mission performance through the thruster operation time $\mathrm{T}$. For $\mathrm{T}>$ thruster life, multiple thrusters are required to perform a mission. This requires redundant thruster sets, and increases the mass of the thrust subsystem. With the above background into the effects of various thruster parameters on mission performance, the high power thruster options currently available can be described with their corresponding parameter ranges defined.

\section{Thruster types}

As will be discussed below, most missions requiring high power also tend to require higher $\mathrm{I}_{\mathrm{sp}}$, that is, values greater than 2000 seconds. This requirement focuses the available electric thrust mechanisms to either electrostatic or electromagnetic propulsion. Electrostatic thrusters use a DC applied electric field to accelerate ions to the desired velocities. Ion and Hall Effect thrusters use this mechanism. Electromagnetic thrusters use the Lorentz force arising from orthogonal currents and magnetic fields $(\boldsymbol{J} \times \mathbf{B})$ to accelerate neutral plasma. Magnetoplasmadynamic (MPD) thrusters and the Pulsed Inductive Thruster (PIT) are electromagnetic.

\section{A. Ion}

\section{Physics}

The ion thruster uses conducting grids to apply a kilovolt $(\mathrm{kV})$ potential gradient to neutral plasma and thereby accelerate ions to high exhaust velocities. For a given voltage, the particle velocity depends on its atomic mass, with heavier ions reaching lower speeds. A schematic of the ion thruster is shown in Figure 1. Plasma is generated in the discharge chamber through electron bombardment. The discharge hollow cathode at the rear of the chamber generates the electrons. The discharge plasma is quasi-neutral - it has zero net electric charge. At the exit of the discharge is the first grid, called the screen grid, which is biased slightly negative to the plasma. This allows ions to drift between the grid holes, into the region between the screen grid and the accelerator gird (also called accel grid). The $\mathrm{kV}$ potential is applied between the screen and accel grids to drive the ions to high $\mathrm{I}_{\mathrm{sp}}$. Upon exiting the accel grid, the ion beam is neutralized external to the thruster by a neutralizer cathode. 


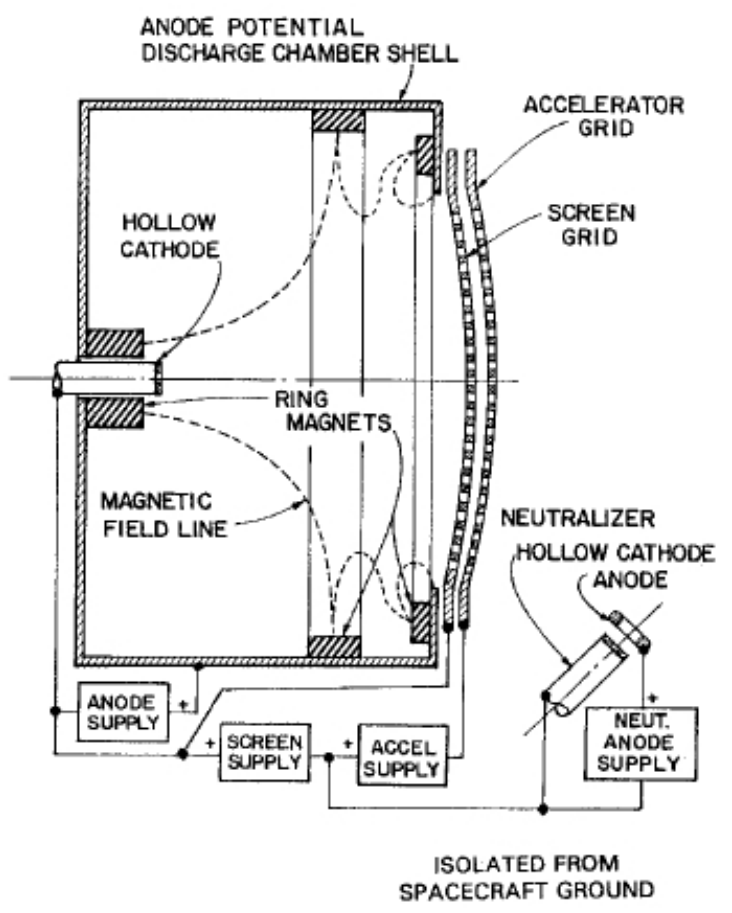

Figure 1.- Ring-Cusp Ion Thruster Schematic. ${ }^{4}$

The ion current through the grids is limited by several factors. First, the space-charge limited current density restricts the amount of current that can flow across a potential gap without shielding out the potential. Second, the grids are exposed to impacts from the high-speed ions, as well as from high-speed neutrals generated by chargeexchange collisions with neutral gas near the grids. Such impacts can sputter material from the grids, eroding them with time. To allow grid lifetimes comparable with mission operation times ( 10-20,000 hours, typically), the allowable erosion rates translate to a maximum current flux through the grids. In general, grid life, in particular accel grid life tends to be the limiting factor in determining current flux. ${ }^{5}$

\section{Figures of Merit}

\section{Specific Impulse, Isp}

For state-of-the-art, low power missions, Isp's from 2000 to $4000 \mathrm{~s}$ are desirable. To achieve this level, Xenon is used as the propellant of choice because of its high atomic mass. These values are obtained with xenon propellant at accelerating voltage levels of 1 to $2 \mathrm{kV}$. Recent work for higher power robotic missions to the outer planets has focused on increasing operating voltage, and therefore Isp, up to $6000-9000 \mathrm{~s}^{6}{ }^{6}$ An alternative approach to reaching higher $I_{\mathrm{sp}}$ values is to use krypton or argon as propellants - because they are lighter, the applied voltage for high $I_{\mathrm{sp}}$ is lower than for xenon. Depending on the choice of propellant, the voltages required would range from 2 up to 10 $\mathrm{kV}$ or more. The appropriate range of operation for the three propellants in terms of $\mathrm{I}_{\mathrm{sp}}$ and efficiency are shown in Figure 2. 


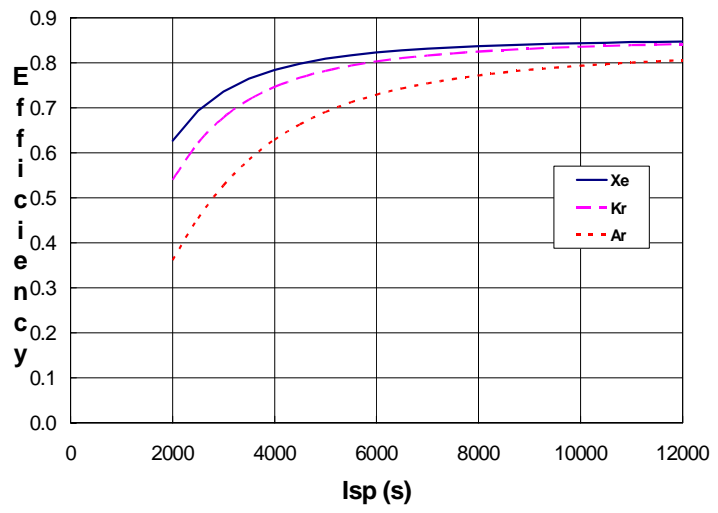

Figure 2.- Representative ion thruster

efficiency, $\eta$, for xenon (Xe), krypton (Kr), and $\operatorname{argon}(\mathrm{Ar})$.

Thruster Efficiency, $\eta$

As can be seen from Figure 2, thruster $\eta$ is quite high over a range of operating conditions. Values greater than $70 \%$ are obtainable with ion thrusters operating at high Isp. Typically, the efficiency for ion thrusters can be described mathematically in the form:

$$
\eta=\frac{b I_{s p}^{2}}{d^{2}+I_{s p}^{2}}
$$

Where $\mathrm{b}$ and $\mathrm{d}$ are empirical terms related to the losses due to plasma production and acceleration. ${ }^{7}$ The corresponding $\mathrm{b}$ and $\mathrm{d}$ parameters for the three propellants discussed are given in Table 1 .

Table 1.-Efficiency coefficients for ion thrusters. ${ }^{3}$

\begin{tabular}{|c||c|c|}
\hline Propellant & b & d (ks) \\
\hline \hline Xenon & $\mathbf{0 . 8 6}$ & 1.21 \\
\hline Krypton & $\mathbf{0 . 8 6}$ & 1.53 \\
\hline Argon & $\mathbf{0 . 8 4}$ & 2.29 \\
\hline
\end{tabular}

\section{Lifetime}

Ion thrusters have demonstrated lifetimes up to $30,000 \mathrm{~h}$ in laboratory life tests, and up to $8000 \mathrm{~h}$ in flight operation. ${ }^{8}$ As described previously, the thrusters were designed with current densities low enough to keep accel grid wear to acceptable limits over the thruster life. Additional life limiting components included the discharge chamber hollow cathode and neutralizer cathode. The discharge cathode, in particular, is subject to ion sputter damage. In one life test, the cathode cover eroded completely away, although the cathode continued operating. Recent thruster designs at the $20-40 \mathrm{kWe}$ level are for $15,000 \mathrm{~h}^{6,9}$

\section{Scaling to high power}

The majority of power input to ion thrusters is deposited in the exhaust beam, so that $P_{e} \sim j_{b} A_{g} V_{b}$. $J_{b}$ is the ion current flux through the grids, $A_{g}$ is the grid area, and $V_{b}$ is the voltage to which the ions are accelerated. $V_{b}$ is determined by the ion species (atomic mass) and the $\mathrm{I}_{\mathrm{sp}}$. $\mathrm{J}_{\mathrm{b}}$ is determined by the grid lifetime, propellant species, and voltage across the grids. To increase thruster power at fixed $\mathrm{I}_{\mathrm{sp}}$, therefore, essentially requires a larger area thruster. However, increasing the thruster area while maintaining a uniform small intergrid spacing presents structural challenges to designing a reliable thruster, particularly when vibration due to launch are considered. 
An earlier study based on the space-charge limited current density, but neglecting accel grid wear, resulted in a 7800 $\mathrm{s}, 1.25 \mathrm{MW}_{\mathrm{e}}$ argon ion thruster requiring rectangular grids $1 \mathrm{~m}$ by $5 \mathrm{~m}^{7}$. More recent calculations based on accel grid lifetime could increase the required grid area for $1 \mathrm{MW}_{\mathrm{e}}$ to 15 square meters or more at comparable $\mathrm{I}_{\mathrm{sp}}$ levels. ${ }^{10}$

\section{B. Hall Effect Thrusters}

1. Physics

Hall effect thrusters combine a static radial applied magnetic field with an axial electric field to operate as electrostatic accelerators without grids. A Hall schematic is shown in Figure 3. Concentric cylindrical magnet poles at the exit of the device impose the radial field. An anode at the rear of the device generates the plasma from which the ions are accelerated. An external cathode injects electrons down a voltage gradient between the anode and cathode. The electrons are trapped by the radial magnetic field in a circular Hall current; the magnetic field is designed so that ions are not trapped.

\section{Figures of Merit}

\section{Specific Impulse, Isp}

Hall Thrusters have been primarily operated using Xenon (Xe) propellant in the 1000-3300 s range of $\mathrm{I}_{\mathrm{sp}}$. Recently, the NASA-457M thruster was operated on Krypton (Kr) up to $4500 \mathrm{~s}$ and at power levels up to $70 \mathrm{kWe}$. $\mathrm{I}_{\mathrm{sp}}$ 's as high as $8000 \mathrm{~s}$ have been projected for a two-stage Hall thruster operating on bismuth; however this has not been experimentally verified. ${ }^{12}$ For operation with Xenon propellant, the above $\mathrm{I}_{\mathrm{sp}}$ 's were achieved at discharge voltages of 300-600 V. Increased $I_{\mathrm{sp}}$ ranges were obtained for voltages of $1 \mathrm{kV}$.

\section{Thruster Efficiency, $\eta$}

Hall thrusters operating on Xe have demonstrated discharge efficiencies up to $70 \%$ in the $\mathrm{I}_{\mathrm{sp}}$ range given above. Operation with $\mathrm{Kr}$ yielded a maximum discharge efficiency of $64 \%$. A projected efficiency value of $80 \%$ has been given for a bismuth propellant Hall thruster, but this has also not been experimentally verified.

\section{Lifetime}

Hall thruster lifetime is limited by erosion of the ceramic chamber walls. Lifetimes up to $7400 \mathrm{~h}$ have been demonstrated in low power devices ${ }^{13}$, based on present technology, lifetimes from $6000-8000 \mathrm{~h}$ might be expected in high power thrusters, depending on the propellant and $\mathrm{I}_{\mathrm{sp}}$ 's required. ${ }^{14}$

\section{Scaling to high power}

Scaling Hall devices to higher powers will require increased thruster diameters and propellant and current throughput. If $\mathrm{I}_{\mathrm{sp}}$ must also be increased, higher discharge voltages and applied fields may also be required. A chief engineering concern will be thermal management of the waste heat deposited into the anode, as well as thermal design of the channel insulators to allow long lived, high temperature operation. ${ }^{14}$

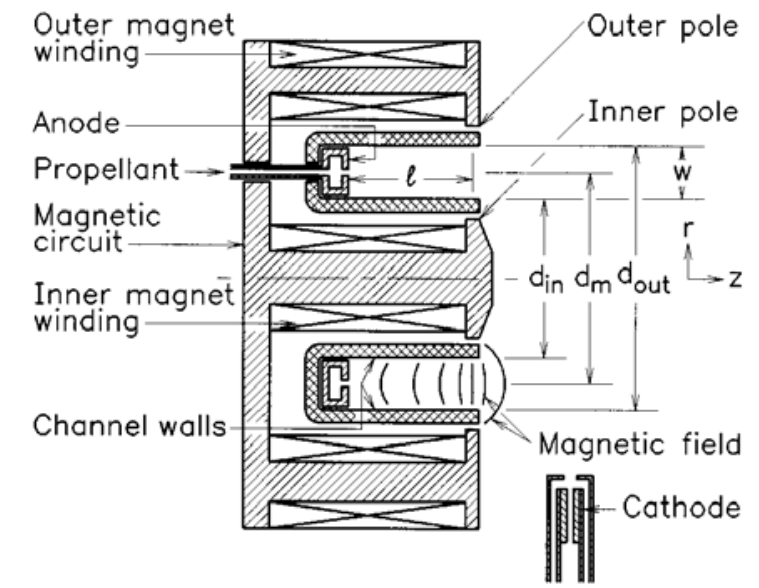

a.)

Figure 3.-Two hall thruster designs: a.) Stationary Plasma Thruster (SPT) b.) Anode Layer Thruster (TAL).

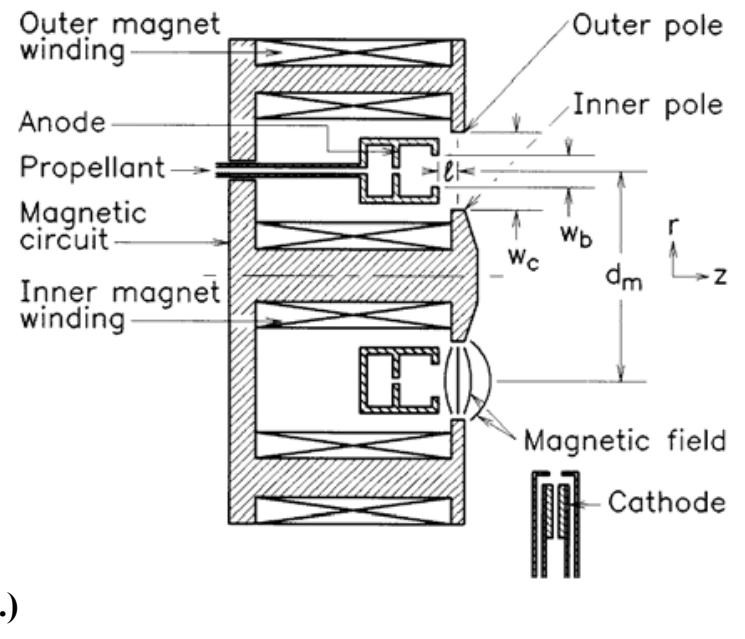

b.) 


\section{Magnetoplasmadynamic (MPD) Thrusters \\ 1. Physics}

MPD thrusters utilize the Lorentz force resulting from orthogonal currents and magnetic fields to accelerate neutrally charged plasma to high velocities. Because of this, they are sometimes also referred to as Lorentz Force Accelerators. The concepts currently under consideration are cylindrical, with an inner central cathode and an outer coaxial anode (Figure 4). The acceleration processes inherent in these devices can be separated into two classes. In the first, the magnetic fields in the thruster are generated by the flow of current across the inter-electrode gap and along the cathode. This form is called "Self-field" thrust. An external axial magnetic field can also be applied to the thruster. This is referred to as the "applied-field" thruster ${ }^{15}$.

In the self-field thruster, the thrust is dependent purely upon the current and thruster geometry, through the relation $\mathrm{T}_{\mathrm{MPD}}=\mathrm{b} \boldsymbol{J}^{2}$, where $\mathrm{b}$ is a geometric parameter and $\boldsymbol{J}$ is the current through the device. The applied-field thruster has been observed to augment the self-field thrust in some cases, although the mechanisms by which additional thrust is generated are not well understood. ${ }^{16}$ Because of the electromagnetic nature of these thrusters, they operate at high currents and low voltages. They have also demonstrated their most efficient performance at $>$ MW power levels. At these levels the current is on the order of kAmperes and the voltages are 200-400 V.

Because of the dearth of MW level space power supplies, and the difficulties of steady state testing at MW levels (more accurately, at the $\mathrm{g} / \mathrm{s}$ flow rates that are required at MW levels), MPD thruster development has been sporadic, with limited opportunities for uninterrupted research and optimization. ${ }^{17}$ A majority of the thruster testing has been using argon as a propellant, strictly from an availability basis. The two propellants identified as preferable for high performance operation are hydrogen or lithium.

\section{Figures of Merit}

Specific Impulse, Isp

MPD thrusters have been operated with a variety of propellants from 1000 to over $10,000 \mathrm{~s} \mathrm{I}_{\mathrm{sp}}$. A caveat to this range is that a limiting aspect of MPD thruster operation is the "onset" limit, a phenomenon which occurs at high ratios of $\boldsymbol{J}^{2} / \dot{\mathrm{m}}$. At onset, high amplitude, high frequency voltage oscillations occur, and they are accompanied by a marked increase in anode erosion. This limit can also effectively limit the maximum $\mathrm{I}_{\mathrm{sp}}$ of the MPD thruster. Extension of this limit is an ongoing avenue of research. $\mathrm{I}_{\mathrm{sp}}$ 's ranging from 2000-8000 s are possible with lithium ${ }^{18}$, hydrogen operation results in values from 5000 to over $10,000 \mathrm{~s} .{ }^{19}$
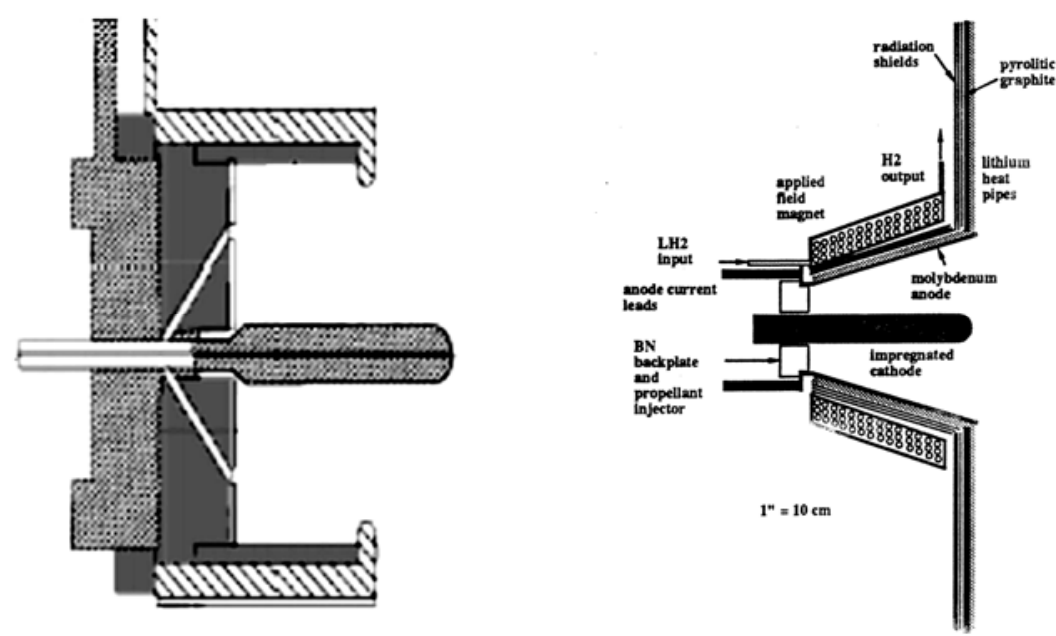

Figure 4.-Self- (left) and Applied-Field (right) MPD Thruster Schematics. 

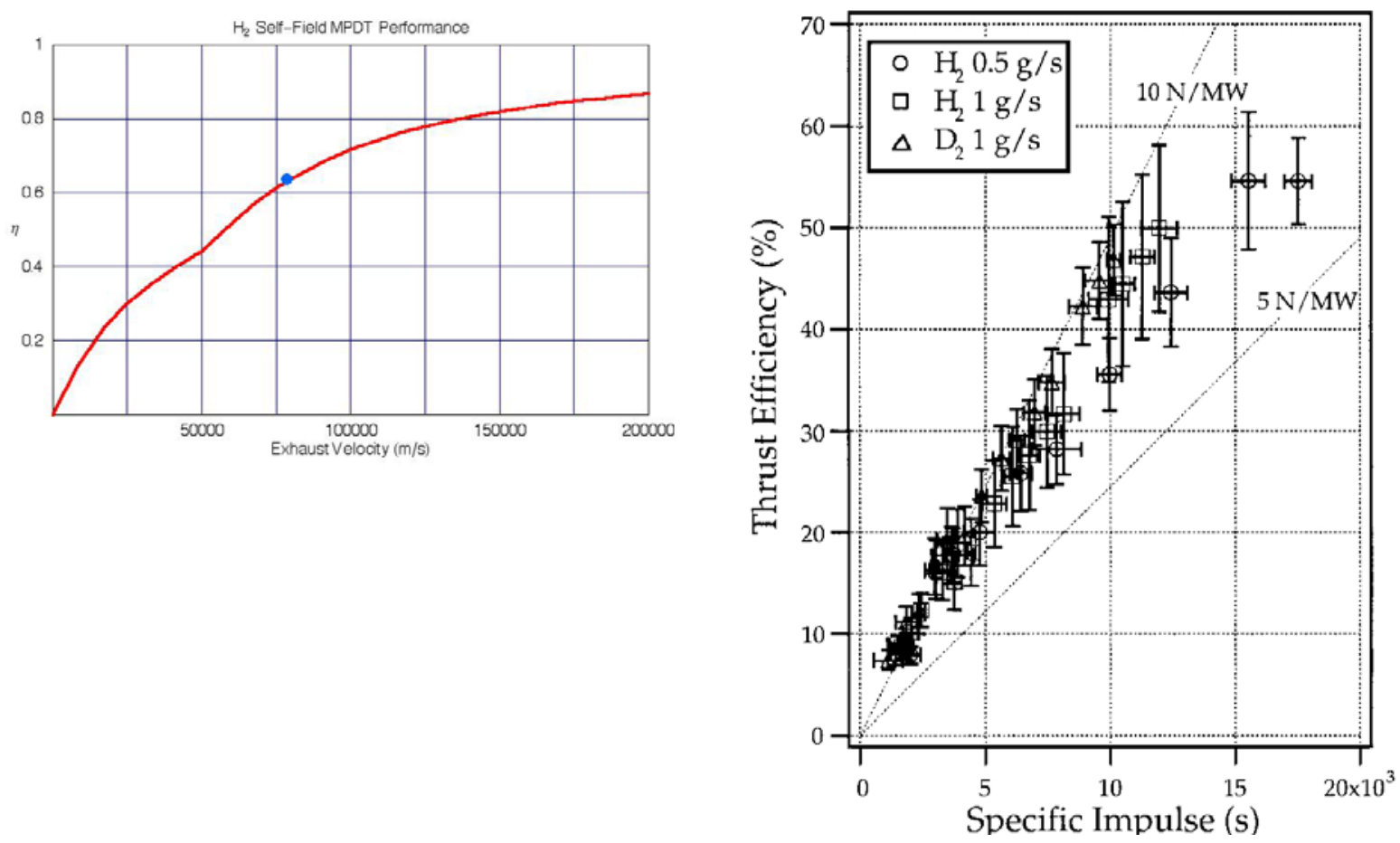

Figure 5.- Projected $^{20}$ and measured ${ }^{19}$ self-field MPD thruster performance using hydrogen.

Thruster Efficiency, $\eta$

Projected maximum thruster efficiencies range from $60 \%$ at over $8,000 \mathrm{~s}$ with hydrogen ${ }^{20}$, and $65 \%$ at $8000 \mathrm{~s}$ with lithium. Measured efficiencies thus far are $55 \%$ at $6000 \mathrm{~s}$ with lithium, and $50 \%$ at $15000 \mathrm{~s}$ with hydrogen. ${ }^{19}$ Example self-field projected and measured performances are shown in Figure 5. The projected increase in efficiency is assumed to come from optimized thruster geometry and mass flow distribution, but has not yet been experimentally proven ${ }^{21}$.

\section{Lifetime}

Both the extension and measurement of lifetime remain issues in MPD thruster operation. Operating below onset, MPD thruster lifetime is determined by the lifetime of the cathode. The cathode is exposed to high current densities and high velocity plasma. Cathode mass loss due to localized evaporation from small, high-current current attachment points distributed over the surface can be ameliorated by using low work function materials and operating at a temperature high enough to allow thermionic emission of the necessary current ${ }^{7}$. The cathode erosion is then caused by sputtering by the high velocity ions at its surface. Lifetimes of at least $5000 \mathrm{~h}$ are needed to make MPD thrusters relevant to missions of interest.

\section{Scaling to high power}

While the plasma physics of MPD thrusters favor high power, some engineering concerns remain. In the case of lithium thrusters, propellant management and distribution of a room temperature solid must be addressed, including propellant heaters, pumps, and valves. If applied field coils are used, either a normal conductor coil can be used with accompanying power losses and heat dissipation, or a superconducting coil with its attendant cooling and insulation requirements. For either thruster, a majority of the wasted heat is deposited in the anode, and must be rejected either through radiation or active cooling ${ }^{7}$. 


\section{PIT}

\section{Physics}

The PIT is also an electromagnetic accelerator using the same Lorentz force as the MPD, but in different topology. A PIT schematic and test device are shown in Figure 6. The PIT consists of a flat multi-turn coil powered by a pulse-forming network. A mass injection system in front of the coil sends a mass pulse of propellant backward to cover the coil surface with a uniform gas layer. The pulse forming network discharges through the coil, producing a $\mu$ s pulsed radial magnetic field at the surface of the coil. By Faraday's law, the changing magnetic field induces an azimuthal electric field in the gas layer, ionizing the gas to plasma and driving a current through the plasma. The interaction of $\boldsymbol{J}_{\boldsymbol{\theta}} \times \mathbf{B}_{\mathrm{r}}$ results in an axial force that ejects the plasma loop at high speeds.

Because the current is induced, the PIT is inherently a pulsed device. Charging voltages at performance levels of interest are in $5-15 \mathrm{kV}$ range, and experimental pulse energies are on the order of kJ. Pulse lengths are typically 5-10 $\mu$ s long, giving instantaneous power readings in the MWe. Experimental results to date have been in a singleshot mode, rather than in repetitive operation; the average power of the PIT in repetitive operation would depend on the duty cycle ${ }^{22}$. The optimal size of this thruster has been determined to be $\sim 1 \mathrm{~m}$. Test data described below are for this optimal diameter coil.

\section{Figures of Merit}

\section{Specific Impulse, Isp}

The PIT has been operated on a wide variety of propellant types: argon, ammonia, hydrazine, and helium. In ammonia, $\mathrm{I}_{\mathrm{sp}}$ 's from $500 \mathrm{~s}$ up to $8000 \mathrm{~s}$ have been measured. Ammonia is currently the propellant of choice, having demonstrated the highest performance for reasons that are not yet fully understood. ${ }^{23,24}$

Thruster Efficiency, $\eta$

PIT efficiency in ammonia has been measured up to $55 \%$ at $5000 \mathrm{~s}$. The variation in efficiency is relatively low (between 50 and 55\%) over a range of $\mathrm{I}_{\mathrm{sp}}$ from 4000 to $9000 \mathrm{~s}$, which is fairly unique in electric propulsion. Results for other propellants are generally below $50 \%$ for any $\mathrm{I}_{\mathrm{sp}}$. The highest efficiency was measured at the highest charging voltage of $16 \mathrm{kV}$.

\section{Lifetime}

Because the PIT has not been operated in a repetitive mode, lifetime is unknown. However, the fact that the device has no metallic electrodes exposed to high velocity plasma mitigates the life limiting material issue inherent in the steady state devices described previously. Conversely, the pulse forming and switching electronics which accompany this device will have to operate reliably for millions of pulses at instantaneous powers of MW, which is an outstanding challenge to this device. Experimental switching was done with spark gaps; this technology reintroduces electrodes to the system and reduces the lifetime advantage of the electrodeless coil. Solid state switching would be required for an operational device.
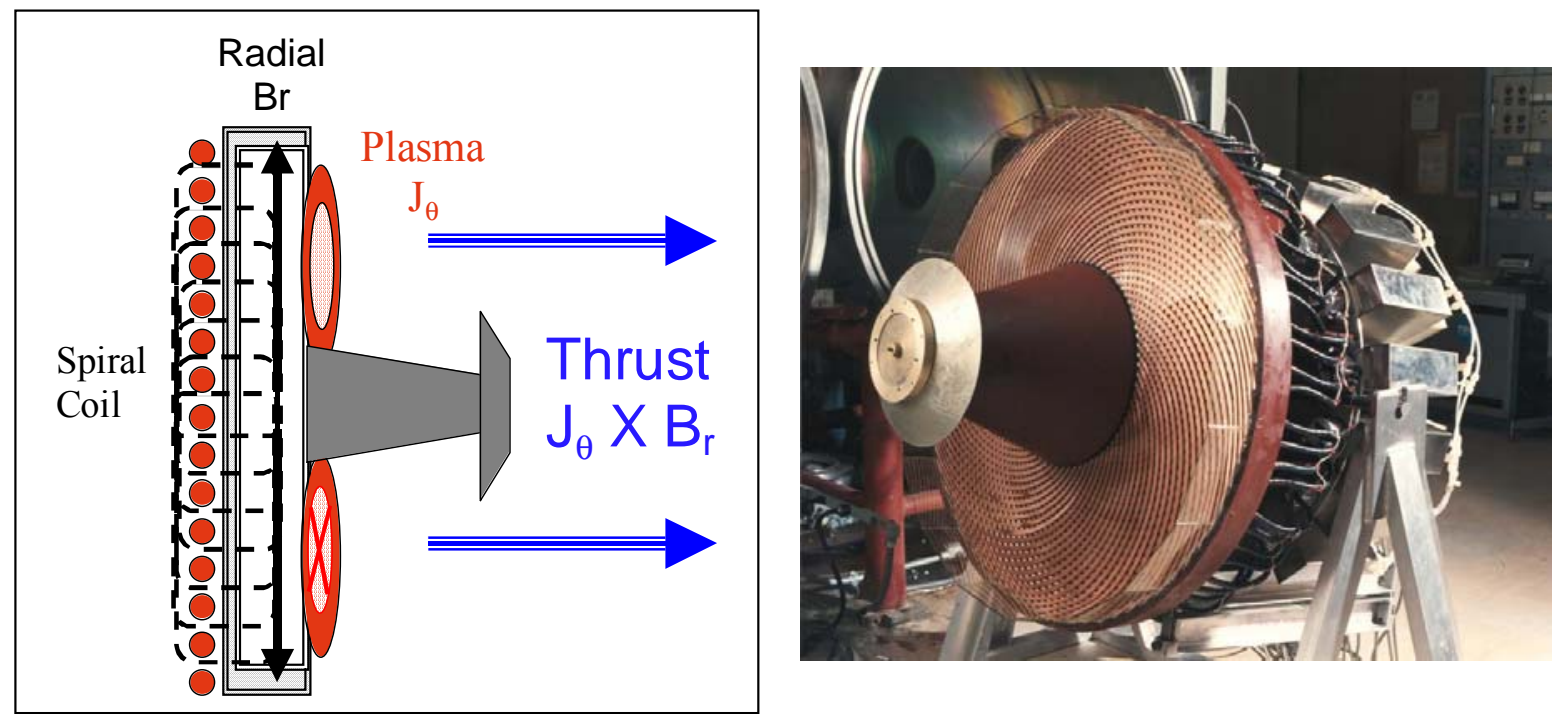

Figure 6.-_Pulsed Inductive Thruster (PIT) operation schematic (left) and operational device (right) ${ }^{22}$. Device diameter is $\sim 1 \mathrm{~m}$. 


\section{Scaling to high power}

In essence, scaling the PIT to MWe levels is a matter of high rep rate operation. The size of the thruster is optimized for single pulse performance, so no change in thruster dimension is required. The engineering issues that arise are the durability of the coil and shielding materials to the flexing and impact of the coil during the pulse, the exposure of the coil and shield to UV light from the energetic plasma, and heat management in the coil and pulse network for high rep-rate operation.

\section{Ancillary Issues for High Power EP}

\section{A. Thruster Testing}

For any thruster capable of operation at MWe and thousands of seconds $\mathrm{I}_{\mathrm{sp}}$, testing at propellant mass flow rates on the order of $\mathrm{g} / \mathrm{s}$ is required. This provides a stringent vacuum pumping requirement of $\mathrm{Ml} / \mathrm{s}$, which is available at only a few facilities in the world. Thruster life testing at MWe levels would require such a facility for thousands of hours to provide life data for flight qualification, at least initially. The facility requirements would, of course, depend on propellant choice. Condensable propellants such as lithium or bismuth could be easily cryopumped, but present other safety issues. Noble gases can and are cryopumped in Hall and Ion thruster tests ${ }^{12}$. Requirements for a hydrogen facility are still under definition.

\section{B. Power Processing}

Each thruster concept would require power processing to convert the output power from the power system and transmission lines to a format useful for the thruster. Some of the generic requirements are summarized in Table 2. Regardless of the specific needs, such processing units at MWe levels will have to deal with thousands of volts or amperes reliably and efficiently. At a Power Processing Unit (PPU) efficiency of 0.92 and $1 \mathrm{MWe}$, the heat rejected is $80 \mathrm{kWe}$; more than the total spacecraft power available today. Rejection of this heat at low operating temperatures will drive up the PPU radiator mass and inhibit the acceleration of the vehicle, thus impacting mission performance. It is important that these technologies (which are beyond the scope of this paper) be addressed in concert with the thrusters.

Table 2.-Representative electrical operation requirements for high power thrusters and power processors.

\begin{tabular}{|l|l|l|l|l|}
\hline & Ion & Hall & MPD & PIT \\
\hline Power (kW) & $30-1000$ & $1-500$ & $1000-10000$ & $30-10000$ \\
\hline Voltage & $2-20 \mathrm{kV}$ & $.2-1 \mathrm{kV}$ & $.1-.5$ & Charging to kV \\
\hline Current & $10-100$ & $100-1000$ & $1000-10000$ & 1000 (peak pulse) \\
\hline AC/DC & DC & DC & DC & AC (pulsed) \\
\hline
\end{tabular}

\section{High Power Electric Propulsion Missions}

\section{A. Robotic Missions}

Missions require increasing power levels, to maintain reasonable trip times, as mission difficulty and payload delivery requirements increase. Essentially, a higher thrust, high efficiency power and propulsion system is required. Higher thrust can be obtained in one of two ways, higher power or lower $\mathrm{I}_{\mathrm{sp}}$. Lower $\mathrm{I}_{\mathrm{sp}}$ will provide more thrust at the same power level, however more propellant will be required, thus the system is less efficient. Also, the $\mathrm{I}_{\mathrm{sp}}$ has an optimal value for each mission, and cannot be relied upon to provide the increasing thrust requirement.

Therefore, increased power levels are required for spacecraft to achieve each incremental mission step.

Figure 7.-Mission Performance for Varying Power Level, $\Delta \mathbf{v}$, and Isp.

Figure 7 shows the relationship between power for propulsion, $\mathrm{I}_{\mathrm{sp}}, \Delta \mathrm{v}$, and thrust time. Missions are laid out by means of constant $\Delta \mathrm{v}$ lines. The $\Delta \mathrm{v}$ parameter represents the energy change associated with a particular mission, and is relatively constant for a particular class of spacecraft using similar propulsion systems. Associating the $\Delta \mathrm{v}$ values with missions, one could assume that a Lunar mission would have a $\Delta \mathrm{v}$ of approximately $8 \mathrm{~km} / \mathrm{s}$, a $20 \mathrm{~km} / \mathrm{s}$ $\Delta \mathrm{v}$ mission could be a Mars or comet sample-return mission, a $40 \mathrm{~km} / \mathrm{s} \Delta \mathrm{v}$ mission could be a Jupiter Grand Tour type mission, and a $60 \mathrm{~km} / \mathrm{s} \Delta \mathrm{v}$ mission could be a Pluto/Kuiper Belt Explorer or Interstellar Probe mission. 


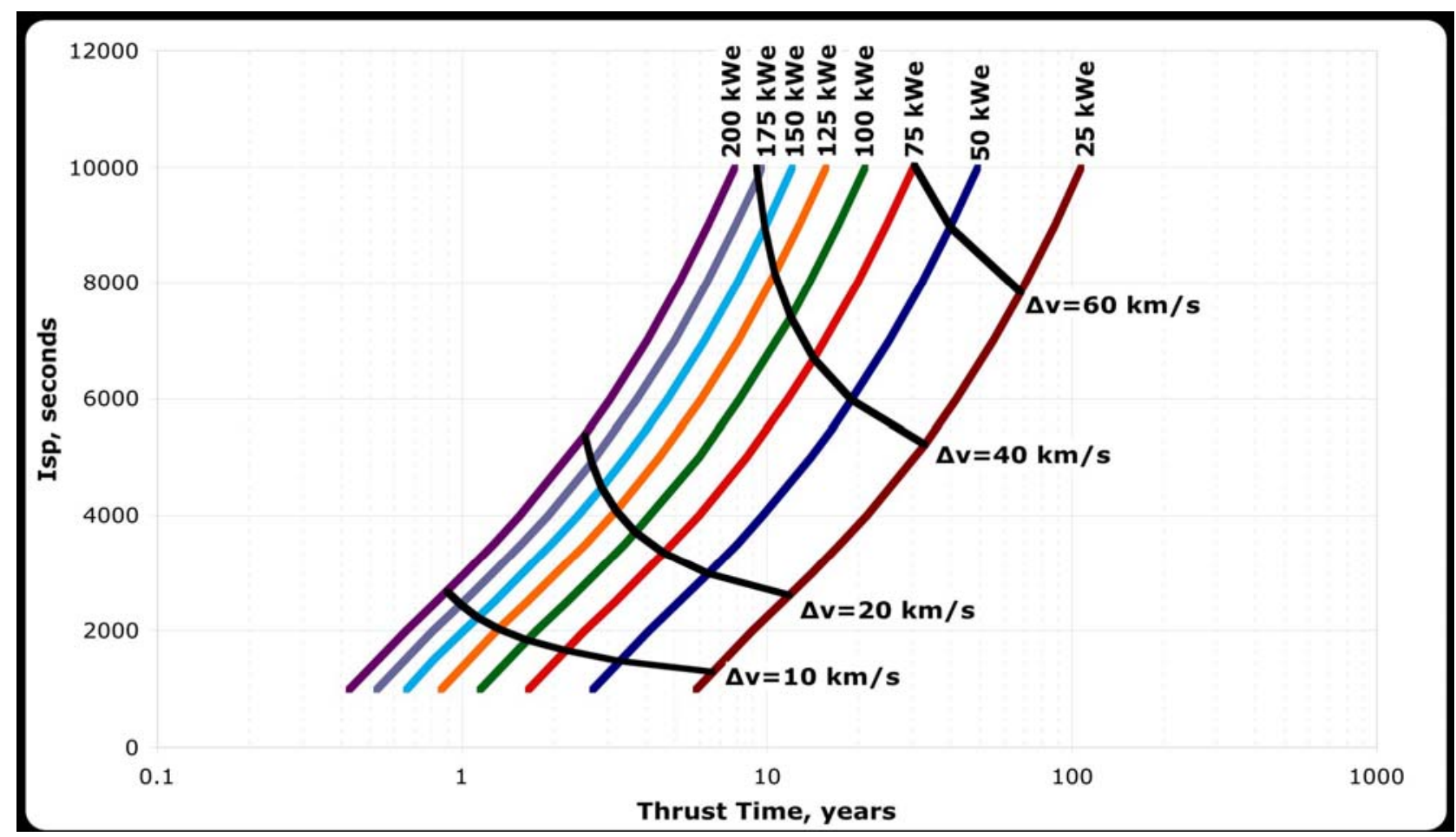

Figure 7.-Mission Performance for Varying Power Level, $\Delta \mathbf{v}$, and Isp.

Electric propulsion (EP) mission performance is highly dependent on both the specific impulse $\left(\mathrm{I}_{\mathrm{sp}}\right)$ of the EP system as well as the power available for thrust ${ }^{25,26}$. Figure 7 assumes a Delta IV Heavy launch to a circular orbit with an altitude of $1000 \mathrm{~km}$. The baseline case is the $100 \mathrm{~kW}$ case at which the spacecraft has a dry mass of 15,000 $\mathrm{kg}$, which includes a $1500 \mathrm{~kg}$ payload. The power system specific mass at $100 \mathrm{~kW}$ is assumed to be approximately $55 \mathrm{~kg} / \mathrm{kW} .{ }^{27}$ The specific mass is scaled to different power levels via an exponential relationship to take into account the economy of scale, that is, higher power levels obtain higher power system specific mass $(\sim 100 \mathrm{~kg} / \mathrm{kW}$ at $25 \mathrm{~kW}$ to $\sim 40 \mathrm{~kg} / \mathrm{kW}$ at $200 \mathrm{~kW}){ }^{27}$

The specific impulse values shown, in Figure 7, for a given power level and $\Delta \mathrm{v}$ can be considered to be the thrust time optimal value of $I_{\mathrm{sp}}$. Increasing or decreasing the $\mathrm{I}_{\mathrm{sp}}$ at the same $\Delta \mathrm{v}$ and power level will lengthen the thrust time required for the mission. As $\mathrm{I}_{\mathrm{sp}}$ increases, the acceleration of the spacecraft decreases, and the longer thrust time cannot be recovered by the reduction in propellant causing higher acceleration. Conversely, as $I_{\mathrm{sp}}$ decreases, the acceleration increases, but the increase in propellant mass still causes a lower acceleration than at the optimal $\mathrm{I}_{\mathrm{sp}}$. By examining Figure 7, one can see that for a particular mission a reduction in thrust time can be achieved by increasing the $\mathrm{I}_{\mathrm{sp}}$ and power. However, the benefits of increasing power are diminished, for these cases, as the power level increases past $100 \mathrm{~kW}$. Note that changing the baseline assumptions, the launch vehicle or dry mass, will vary the relationships shown in Figure 7. 


\section{B. Lunar Cargo Missions}

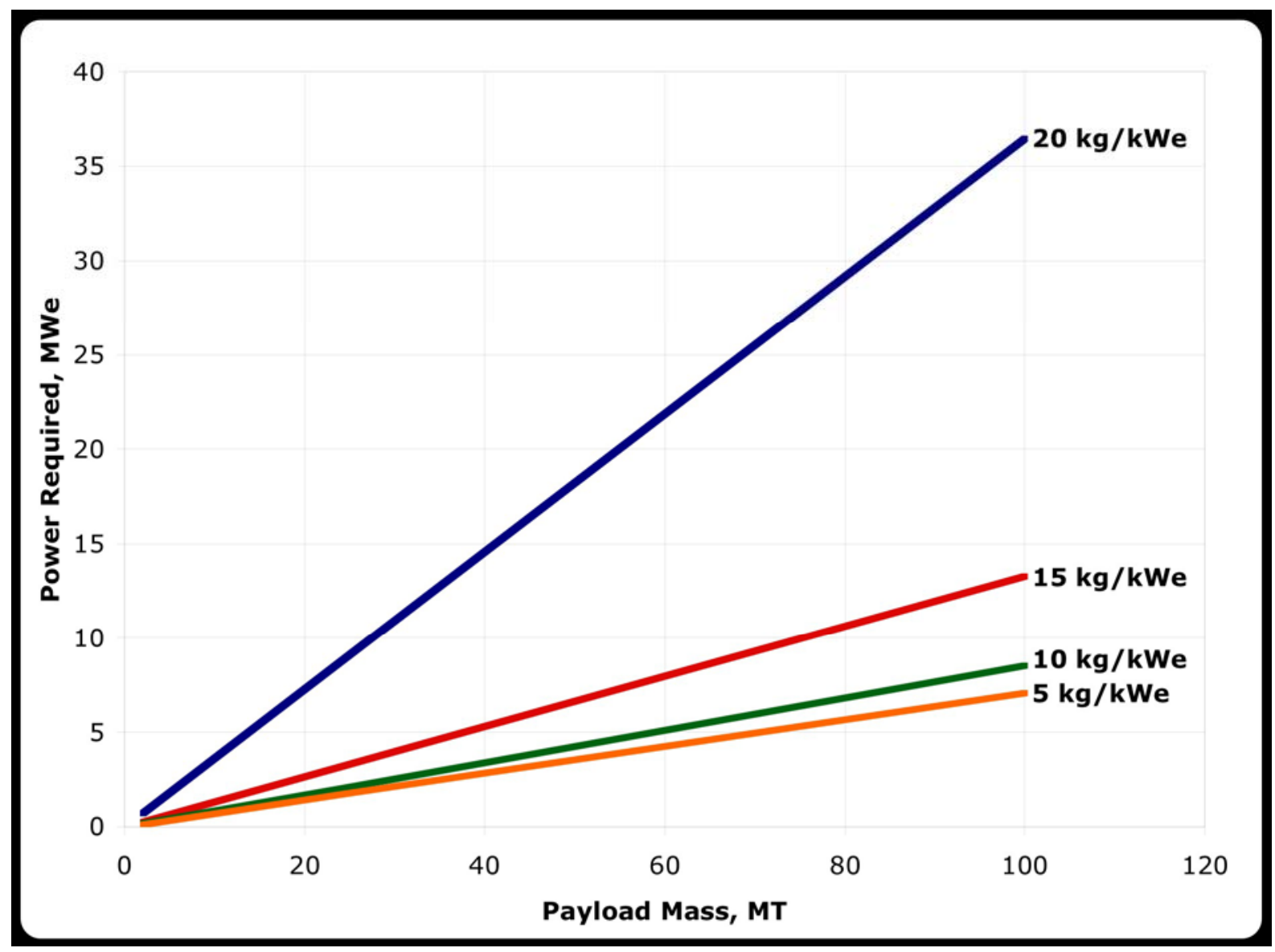

Figure 8. - Optimal Power Levels for Lunar Cargo Missions with Varying Payload Masses at Different Power and Propulsion System Specific Masses, 65 days of Thrusting Time.

Lunar cargo missions will be required in support of the manned lunar missions spelled out in "The Vision for Space Exploration., ${ }^{28}$ To efficiently deliver large amounts of cargo, high power EP systems may be used. In order to deliver the most cargo mass per unit of power, these power and propulsion systems will need to have the minimum specific mass possible.

Figure 8 shows the power requirements for different payload masses and power and propulsion system specific masses for a lunar mission requiring 65 days of thrusting to reach low lunar orbit. $\mathrm{I}_{\mathrm{sp}}$ 's for these specific masses ranged from 4800 seconds at $5 \mathrm{~kg} / \mathrm{kWe}$ to 2800 seconds at $20 \mathrm{~kg} / \mathrm{kWe}$. As expected, higher power levels are required to deliver more payload mass to the Moon. However, this increase in power can be reduced with advanced power and propulsion systems that provide lower specific mass.

\section{Mars Piloted Missions}

High power EP is also applicable to piloted missions to Mars. The baseline architecture assumption for this piloted Mars analysis is that the payload includes a 33.5 MT crew habitat and a 4.5 MT return capsule. A 2022 launch date is targeted with only the outbound, Earth-Mars, leg analyzed. The Earth-departure assumption is that 
the spacecraft is launched to low-Earth orbit where it is assembled (if necessary) and then is flown autonomously towards Earth escape. Approximately $90 \%$ of the way to Earth escape, the crew rendezvous occurs with the EP spacecraft, via another launch, where the piloted mission begins.

Two configurations, all-EP and EP with aerocapture, were analyzed at 10 and $20 \mathrm{~kg} / \mathrm{kWe}$ power and propulsion specific masses (see Fig. 9). For the shortest piloted trip times, which are essential for piloted missions, high power levels are required. Depending on the propulsion system configuration and power and propulsion system specific mass, the power required for propulsion for a 150-day one-way transit ranges between 2 and $7 \mathrm{MWe}$. The $\mathrm{I}_{\mathrm{sp}}$ 's for a 150-day one-way transit range between 2000 and 4000 seconds depending on configuration and power and propulsion system specific mass.

\section{Conclusion}

As shown in Figure 10, electric propulsion offers many benefits when compared with chemical propulsion for the applications displayed in the chart. A wide range of electric propulsion options is being developed at NASA Glenn for use in all future NASA missions. The selection of a propulsion (and power) system depends on the mission requirements. In order for the propulsion system to take full advantage of the development of higher power capabilities on spacecraft, higher power electric propulsions systems are ideal. Their greater fuel efficiency and compatibility with nuclear and solar-power systems are great assets for mission designers. The Lunar/Mars Exploration Initiative will benefit from the development of many of these electric propulsion concepts.

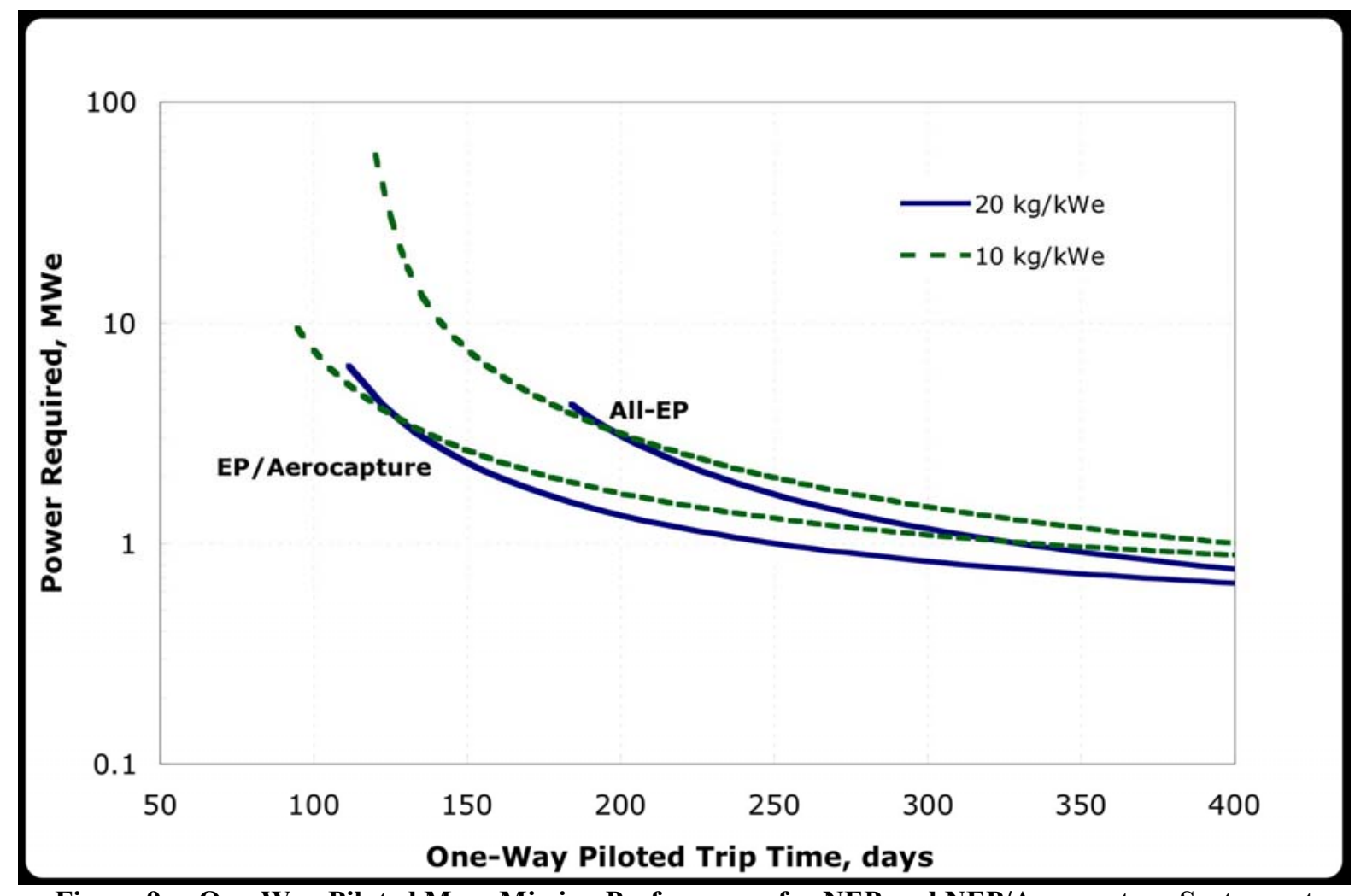

Figure 9.—-One-Way Piloted Mars Mission Performance for NEP and NEP/Aerocapture Systems at Different Power and Propulsion System Specific Masses. 

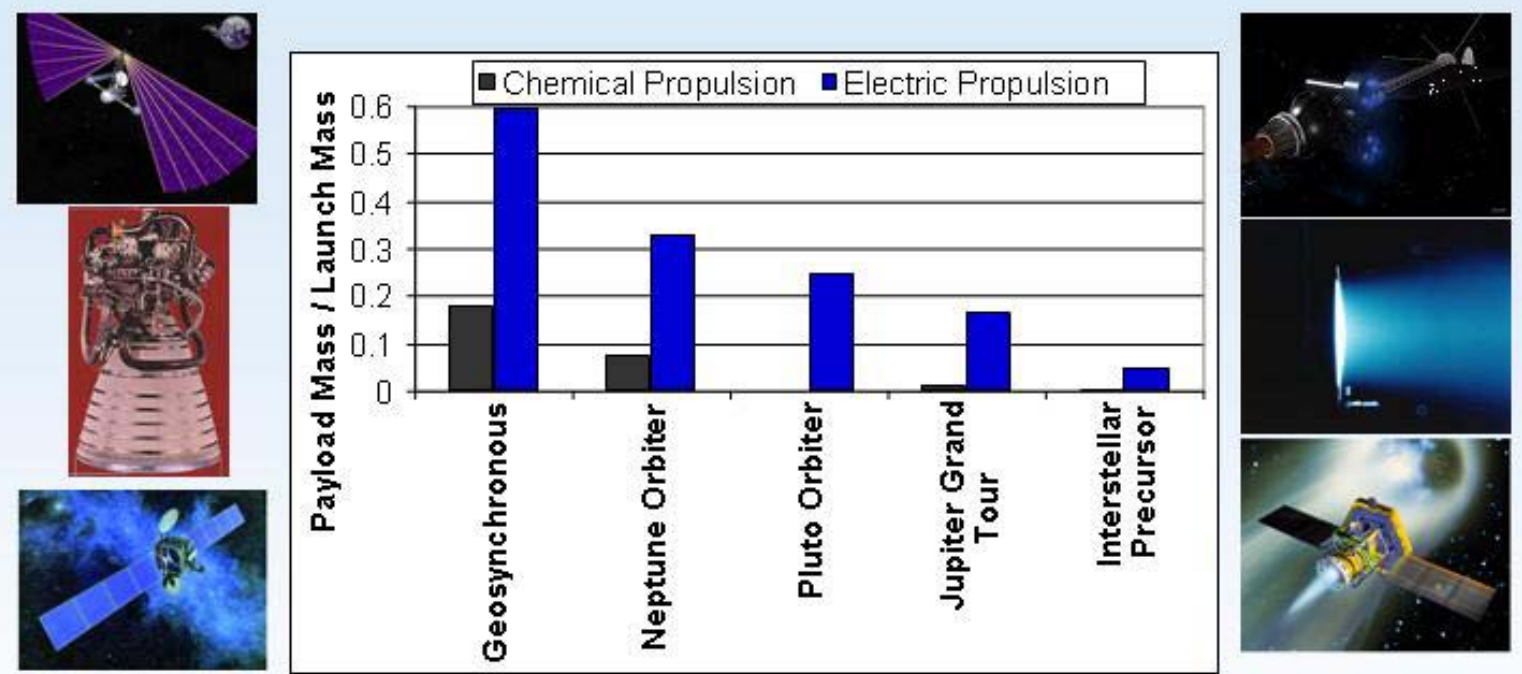

\section{- High Fuel Efficiency Enables Missions (High Isp) \\ - EP provides 2 to 10 times payload increases compared to chemical \\ - EP reduces trip time up to 3 times for many missions}

Figure 10.-Electric Propulsion Benefit for Various Missions

\section{References}

1. Melbourne, W.G. "Interplanetary Trajectories and Payload Capabilities of Advanced Propulsion Vehicles," Technical Report No. 32-68, Jet Propulsion Laboratory, Pasadena, CA 1961.

2. Gilland, J., "NEP Mission Sensitivities to System Performance," in Proceedings of the Ninth Symposium on Space Nuclear Power Systems, Albuquerque, NM, 1992.

3. Gilland, J., "Mission and System Optimization of NEP Vehicles for Lunar and Mars Missions," International Electric Propulsion Conference Paper No. 91-038, Viareggio, Italy, October 1991.

4. Wilbur, P.J., V.K. Rawlin, and J.R. Beattie, "Ion Thruster Development Trends and Status in the United States," J. Prop. And Power, 14 (5) 1998.

5. Wilbur P., Beattie, J. and Hyman, J., “An Approach to the Parametric Design of Ion Thrusters," International Electric Propulsion Paper No. 88-080.

6. Foster, J. et al., "The High Power Electric Propulsion (HiPEP) Ion Thruster," AIAA Paper No. 2004-3453.

7. Gilland, Myers, and Patterson, "Multimegawatt Electric Propulsion System Design Considerations," AIAA Paper No. 91-2552.

8. “Electric Propulsion,” Aerospace America, AIAA, December, 2003, pp. 60.

9. Randolph, T. and J. Polk, "An Overview of the Nuclear Electric Xenon Ion System (NEXIS) Activity", AIAA Paper No. 2004-3450.

10. Patterson, M, R. Roman, and J. Foster, "Ion Engine Development for Interstellar Precursor Missions," AIAA Paper No. 2000-3811.

11. Jacobson D, and D. Manzella, “50 kW Class Krypton Hall Thruster Performance,” AIAA Paper No. 2003-4550.

12. Manzella, D., R. Jankovsky, R. Hofer, “Laboratory Model 50 kW Hall Thruster,” AIAA Paper No. 2002-3676.

13. Gulczinski, F, and R.A. Spores "Analysis Of Hall-Effect Thrusters And Ion Engines For Orbit Transfer Missions," AIAA Paper No. 96-2973.

14. Jankovsky, R., S. Tverdokhlebov, and D. Manzella, "High Power Hall Thrusters," AIAA Paper No. 99-2949.

15. Jahn, R.G., Physics of Electric Propulsion, McGraw Hill, New York, 1968

16. Gilland, J. "System Level Models of Self- and Applied-Field MPD Thrusters," AIAA Paper No. 2004-3470.

17. Lapointe, M. "High Power MPD Thruster Performance Measurements," AIAA Paper No. 2004-3467, 2004.

18. Tikhonov, V.B., et al., "Research of Plasma Acceleration Processes in Self-Field and Applied Magnetic Field Thrusters," in Proc. 23 ${ }^{\text {rd }}$ International Electric Propulsion Conference, IEPC-93-076, Seattle WA, 1993.

19. Choueiri, E.Y. and J. Ziemer, "Quasi-steady Magnetoplasmadynamic Thruster Performance Database," J. Prop. Power, 17 (5) 2001. 
20. McGuire, M. et al., "High Power MPD Nuclear Electric Propulsion (NEP) for Artificial Gravity HOPE Missions to Callisto," in Proceedings of the Space Technology and Applications Forum, STAIF-2003, February 2-5, 2003, Albuquerque, NM.

21. Gilland, J. and G. Johnston, "MPD Thruster Performance Analytic Models," in Proceedings of the Space Technology and Applications Forum, STAIF-2003, Albuquerque, NM, February 2-5, 2003.

22. Dailey, C. Lee and R.H. Lovberg, “The PIT MkV Pulsed Inductive Thruster,” NASA CR 191155, July 1993.

23. Mikellides, P., "Numerical Simulation of the Pulsed Inductive Thruster" Space Technology and Applications International Forum-STAIF 2003, edited by M.S. El-Genk, pp. 540-546, American Institute of Physics.

24. Mikellides, P., "Pulsed Inductive Thruster (PIT): Modeling and Validation Using the MACH2 Code," NASA CR-2003-212714, 2003.

25. Oleson, S.R., "An Analytical Optimization of Electric Propulsion Orbit Transfer Vehicles," NASA CR-191129, May 1993.

26. Oleson, S.R., "Influence of Power System Technology on Electric Propulsion Missions," NASA CR-195419, January 1995.

27. Larson, W.J., Wertz, J.R., Space Mission Analysis and Design, Second Edition, Torrance, CA, 1992.

28. "The Vision for Space Exploration," National Aeronautics and Space Administration, February 2004. 
Public reporting burden for this collection of information is estimated to average 1 hour per response, including the time for reviewing instructions, searching existing data sources, gathering and maintaining the data needed, and completing and reviewing the collection of information. Send comments regarding this burden estimate or any other aspect of this
collection of information, including suggestions for reducing this burden, to Washington Headquarters Services, Directorate for Information Operations and Reports, 1215 Jefferson Davis Highway, Suite 1204, Arlington, VA 22202-4302, and to the Office of Management and Budget, Paperwork Reduction Project (0704-0188), Washington, DC 20503.

\begin{tabular}{|l|l|l} 
1. AGENCY USE ONLY (Leave blank) & $\begin{array}{c}\text { 2. REPORT DATE } \\
\text { March } 2005\end{array}$ & $\begin{array}{c}\text { 3. REPORT TYPE AND DATES COVERED } \\
\text { Technical Memorandum }\end{array}$
\end{tabular}

\section{TITLE AND SUBTITLE}

Electric Propulsion Concepts Enabled by High Power Systems for Space Exploration

6. AUTHOR(S)

James Gilland, Douglas Fiehler, and Valerie Lyons

7. PERFORMING ORGANIZATION NAME(S) AND ADDRESS(ES)

National Aeronautics and Space Administration

John H. Glenn Research Center at Lewis Field

Cleveland, Ohio 44135-3191

9. SPONSORING/MONITORING AGENCY NAME(S) AND ADDRESS(ES)

National Aeronautics and Space Administration

Washington, DC 20546-0001
5. FUNDING NUMBERS

WBS-22-972-20-01

8. PERFORMING ORGANIZATION REPORT NUMBER

$\mathrm{E}-14840$

\section{SUPPLEMENTARY NOTES}

Prepared for the Second International Energy Conversion Engineering Conference sponsored by the American Institute of Aeronautics and Astronautics, Providence, Rhode Island, August 16-19, 2004. James Gilland, Ohio Aerospace Institute, Brook Park, Ohio 44142; Douglas Fiehler, QSS Group, Inc., Cleveland, Ohio 44135; and Valerie Lyons, NASA Glenn Research Center. Responsible person, Valerie Lyons, organization code RP, 216-433-5970.

12a. DISTRIBUTION/AVAILABILITY STATEMENT

12b. DISTRIBUTION CODE

Unclassified - Unlimited

Subject Category: 20

Distribution: Nonstandard

Available electronically at http://gltrs.grc.nasa.gov

This publication is available from the NASA Center for AeroSpace Information, 301-621-0390.

13. ABSTRACT (Maximum 200 words)

This paper describes the latest developments in electric propulsion systems being planned for the new Space Exploration initiative. Missions to the Moon and Mars will require these new thrusters to deliver the large quantities of supplies that would be needed to support permanent bases on other worlds. The new thrusters are also being used for unmanned exploration missions that will go to the far reaches of the solar system. This paper is intended to give the reader some insight into several electric propulsion concepts - their operating principles and capabilities, as well as an overview of some mission applications that would benefit from these propulsion systems, and their accompanying advanced power systems.

14. SUBJECT TERMS

Electric propulsion; Space power

17. SECURITY CLASSIFICATION OF REPORT

Unclassified
18. SECURITY CLASSIFICATION OF THIS PAGE

Unclassified
19. SECURITY CLASSIFICATION OF ABSTRACT

Unclassified 

